\title{
1998 revision of the Canadian Asthma Consensus Guidelines
}

\author{
Louis-Philippe Boulet MD FRCPC ${ }^{1}$, Allan Becker MD FRCPC ${ }^{2}$, Denis Bérubé MD FRCPC ${ }^{3}$, \\ Pierre Ernst MD FRCPC ${ }^{4}$, Robert Beveridge MD FRCPC ${ }^{5}$. \\ Asthma Consensus Conference Editorial Committee \\ ${ }^{1}$ Centre de pneumologie, Institut de cardiologie et de pneumologie de l'Université Laval, \\ Hôpital Laval, Sainte-Foy, Québec; ${ }^{2}$ Department of Pediatrics, University of Manitoba, \\ Winnipeg, Manitoba; ${ }^{3}$ Service de pneumologie, Hôpital Sainte-Justine, Montréal; ${ }^{4}$ Division of \\ Clinical Epidemiology, Royal Victoria Hospital, Montréal, Québec; ${ }^{5}$ Atlantic Health Sciences \\ Corporation, Saint John, New Brunswick
}

\begin{abstract}
$\mathrm{A}$ sthma remains one of the major health problems in Canada and worldwide (1). The prevalence of asthma in Canada has markedly increased in the past two decades $(1,2)$. The asthma-related human and socioeconomic burden are still surprisingly high and can be explained, at least partly, by suboptimal clinical management of the disease, particularly with regards to the diagnosis, treatment, education and follow-up of patients with asthma $(3,4)$. A recent national survey of five major groups of physicians by the Laboratory Centre for Disease Control (LCDC) of Health Canada, using methods described by Jin in this issue of the Canadian Respiratory Journal (pages 269-272), found that some recommended asthma management practices have been followed but others have not (4, Jin pages 269-272). Thus, despite a considerable increase in our understanding of asthma physiopathology and the development of new therapeutic agents, asthma care does not seem optimal.

Although criticized at times, therapeutic guidelines remain a useful tool for the clinician, helping to increase awareness of the disease and to define the best options for therapy $(5,6)$. The increasing morbidity and mortality due to asthma observed in the 1970s and 1980s prompted a number of medical societies and international groups to review the state of asthma care and offer guides to treat this disease.

The first Canadian Asthma Consensus Conference took place in Toronto in 1988, under the leadership of Dr Frederick Hargreave, and led to the first comprehensive report on what was considered the optimal approach to asthma management in Canada (7). This has been followed by many national and international consensus statements on asthma management (8-11).
\end{abstract}

In the past decade, these guidelines have been reviewed periodically and, in 1995, the Canadian guidelines for acute asthma management were revised by a group led by Dr Robert Beveridge (12), and guidelines for the chronic management of asthma were revised under the chairmanship of Dr Pierre Ernst (13). These were among the first 'evidence-based' clinical guidelines.

Unfortunately, the dissemination of these guidelines and their ability to modify current practice has been somewhat limited $(4,14,15)$, as confirmed by the recent LCDC survey on medical practices in Canada. Although quite well known by specialists, only a minority of general practitioners said that they knew of the recommendations published.

With these facts in mind and in view of recent progress in asthma research and care, the Asthma Committee of the Canadian Thoracic Society convened a meeting of more than 60 respirologists, pediatricians, allergists, and emergency and family physicians, which took place in Niagara-on-the-Lake, Ontario, from May 28 to 31, 1998. The goals of the meeting were to review and discuss recent developments in the treatment of asthma in order to update the 1995 Canadian Guidelines on asthma for children and adults. Recommendations were based on a critical review of the scientific literature by designated contributors before the meeting, followed by discussions at the Niagara conference, and, finally, a review of the complete proceedings by all participants. Each recommendation was graded according to the strength of sup- 
porting scientific evidence, and the final guidelines will be published in ealry fall in the Canadian Medical Association Journal and specialist journals such as the Canadian Respiratory Journal.

The conference participants retained the concept of the asthma treatment continuum adopted at the 1995 Canadian Asthma Consensus Conference, as reflecting a more dynamic therapeutic approach than stepped care does, and allowing individualization of drug therapy according to the severity of the underlying illness and to the degree of control achieved. The papers presented by keynote speakers have appeared under the heading of "Update in Asthma" in the last few issues of the Canadian Respiratory Journal. Advances in understanding interactions between genetic and environmental factors in asthma were reviewed by Busse (16). Much discussion was devoted to the newer developments in asthma therapy such as leukotriene receptor antagonists (17) and nonchlorofluorcarbon (CFC) inhalers (Dolovich pages 290-295), as well as on the optimal use of agents such as inhaled corticosteroids in children (18) and long-acting beta $a_{2}$-agonists, in the light of major trials published since the previous guidelines were drawn up. The importance of objective measurements of airflow obstruction was confirmed, and new methods to assess airway inflammation (19) were considered promising tools. The major role of psychosocial factors and education in asthma man-

\section{REFERENCES}

1. Sears MR. Epidemiological trends in asthma. Can Respir J 1996;3:261-8.

2. Laboratory Centre for Disease Control, Health Canada. Childhood Asthma in Sentinel Health Units: Report of the Student Lung Health Survey 1995-96. Ottawa: Laboratory Centre for Disease Control, 1998.

3. Krahn MD, Berka C, Langlois P, Detsky AS. Direct and indirect costs of asthma in Canada, 1990. CMAJ 1996;154:821-31.

4. Laboratory Centre for Disease Control, Health Canada. Physician Asthma Management Survey 1996-97. Ottawa, 1998 (unpublished).

5. Gibson P. Asthma guidelines and evidence-based medicine. Lancet 1993;342:1305.

6. Rosenberg W, Donald A. Evidence based medicine: an approach to clinical problem-solving. BMJ 1995;310:1122-6.

7. Hargreave FE, Dolovich J, Newhouse MT. The assessment and treatment of asthma: a conference report. J Allergy Clin Immunol 1990;85:1098-111

8. National Asthma Education Program. Guidelines for the Diagnosis and Management of Asthma. Bethesada: United States Department of Health and Human Services, National Institutes of Health, 1991.

9. Guidelines for the management of asthma: a summary. British Thoracic Society and others. BMJ 1993;306:776-82.

10. Global Strategy for Asthma Management and Prevention: NHLBI/WHO Workshop [publication no 96-3659B]. Bethesda: agement (Kolbe pages 273-280) was also reviewed. The conference organizers are very grateful to the renowned authorities in the field of asthma who provided these overviews of recent developments on these topics, and for making them available to readers of the Journal.

Finally, we should stress that apart from reviewing the different aspects of acute and chronic asthma care, the participants felt that it was mandatory to develop strategies to implement and promulgate the guidelines. An "implementation committee" has been formed, chaired by Dr Dennis Bowie, to examine how the recommendations could be better disseminated to close the gap between what is considered 'optimal' and what is experienced as 'current' care. Although the guidelines are evidence-based, a number of recommendations are not supported by well designed, prospective, randomized studies (Level 1 or 2), and we believe that it is imperative to define the key trials required to increase the level of evidence supporting the recommendations.

We take this opportunity to thank all participants of the Third Canadian Asthma Consensus Conference, the societies, corporations and sponsors of this event, and all those working at developing the implementation strategy. We hope that this exercise will contribute to improved asthma care in Canada and reduce the morbidity associated with this common disease.

United States Department of Health and Human Services, National Institutes of Health, National Heart, Lung and Blood Institute, 1995.

11. International consensus report on diagnosis and treatment of asthma. Clin Exper Allergy 1992;22(Suppl 1):1-72.

12. Beveridge RC, Grunfeld AF, Hodder RV, Verbeek PR, for the CAEP/CTS Asthma Advisory Committee. Guidelines for the emergency management of asthma in adults. CMAJ 1996;155:25-37.

13. Ernst P, Fitzgerald M, Spier S. Canadian Asthma consensus conference: summary of recommendations. Can Respir J 1996;3:89-100.

14. Naylor CD. Grey zones of clinical practice: some limits to evidence-based medicine. Lancet 1995;345:840-2.

15. Woolf SH. Practice guidelines: a new reality in medicine. III. Impact on patient care. Arch Intern Med 1993;153:2646-55.

16. Busse WW. Determinants of risk facotros for asthma. Can Respir J 1999;6:97-101.

17. Wenzel SE. Leukotriene receptor antagonists and related compounds. Can Respir J 1999;6:189-193.

18. Simmons FE. Inhaled glucocorticoids in children: A favourable therapeutic index. Can Respir J 1999;6:175-178.

19. Hargreave FE. Induced sputum for the investigation of airway inflammation: Evidence for its clinical application. Can Respir J 1999;6:169-174 


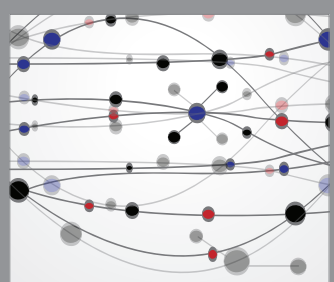

The Scientific World Journal
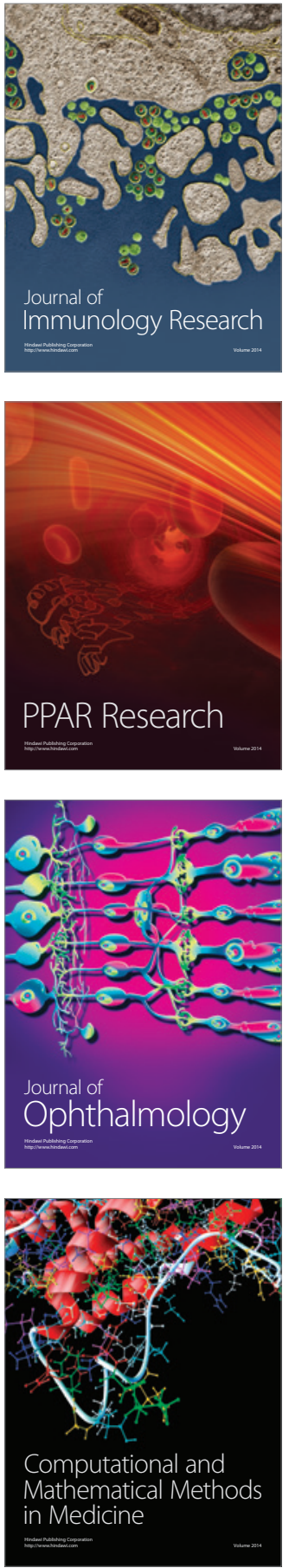

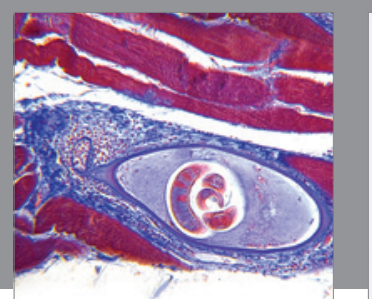

Gastroenterology Research and Practice

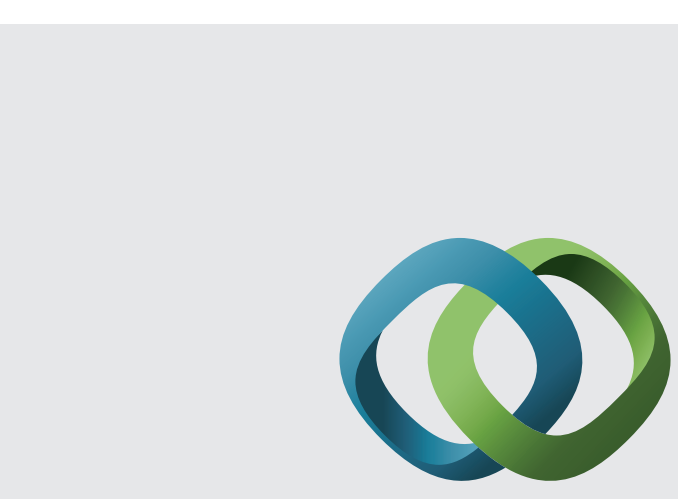

\section{Hindawi}

Submit your manuscripts at

http://www.hindawi.com
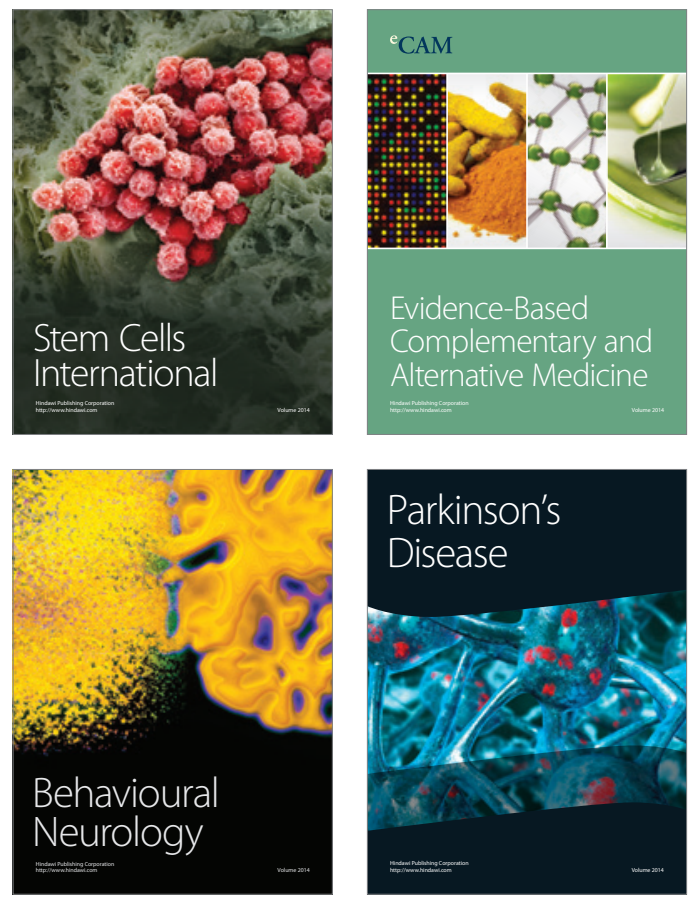
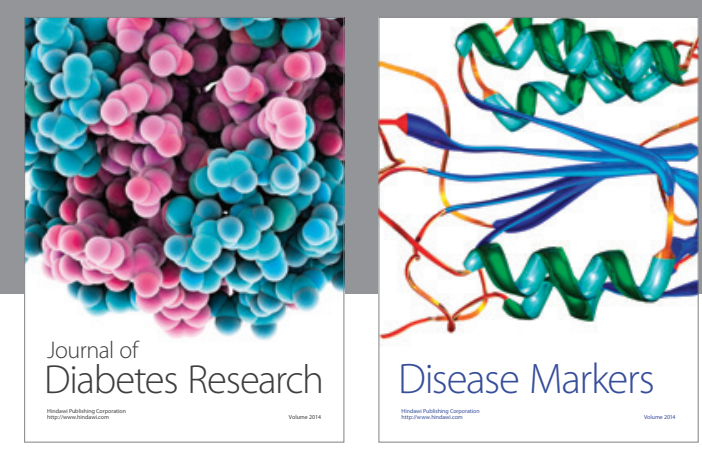

Disease Markers
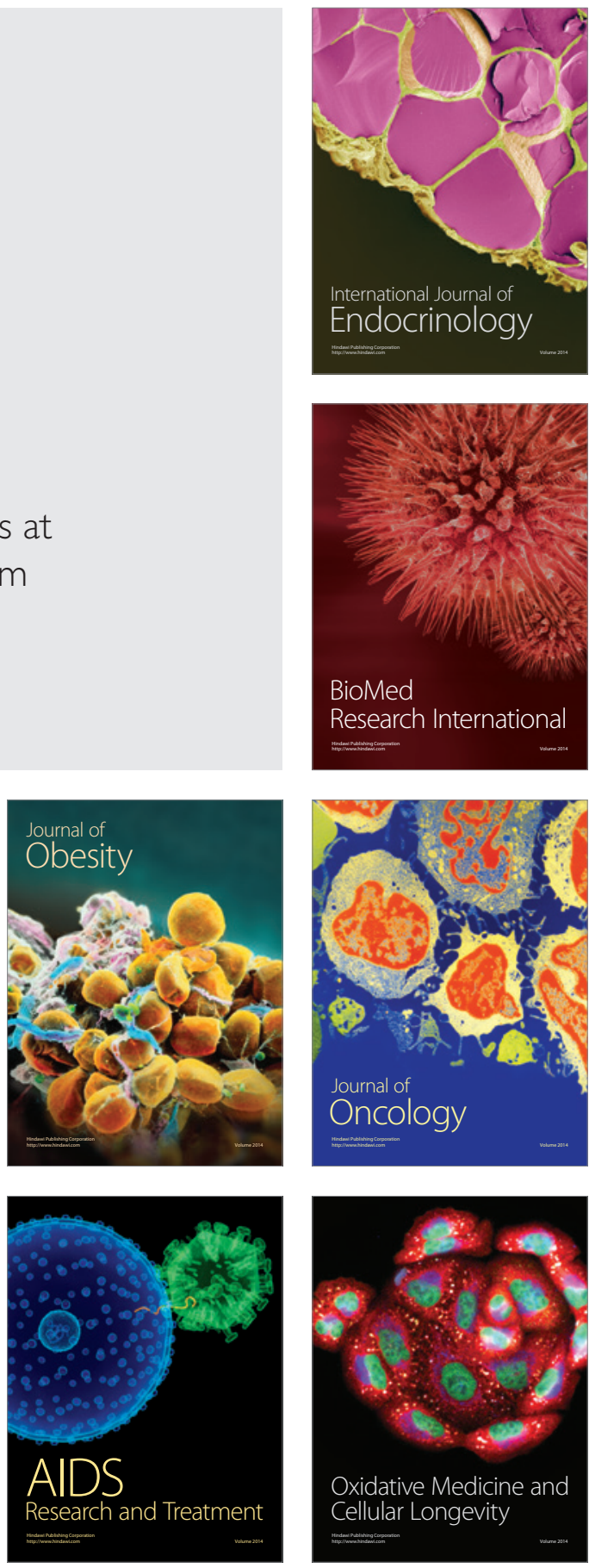